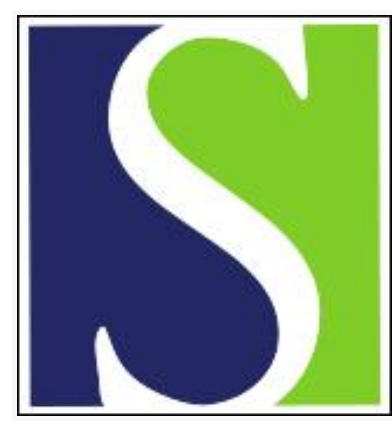

Scand J Work Environ Health 1980;6(3):227-228

https://doi.org/10.5271/sjweh.2613

Issue date: Sep 1980

\title{
Mining, lung cancer and smoking.
}

by Feldstein ML, Band PR

Refers to the following text of the Journal: $1978 ; 4(1): 46-52$

Key terms: cancer; letter to the editor; lung; lung cancer; mining; smoking

This article in PubMed: www.ncbi.nlm.nih.gov/pubmed/6937827

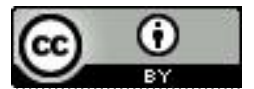




\section{LETTERS TO THE EDITOR}

\section{Mining, lung cancer and smoking}

Sir,

We wish to raise some statistical issues concerning the paper "Mining, lung cancer and smoking" by Drs Axelson and Sundell, which appeared in vol 4 (1978), number 1 of your journal on pages $46-52$. The authors' conclusions, namely, (i) among miners, nonsmokers are more apt to develop lung cancer than smokers and (ii) after induction, lung cancer develops more quickly among smokers than nonsmokers, seem unwarranted on the basis of the data for reasons of both sample size and design.

The points we wish to make are these:

(a) It is a difficult task to determine the relationship between mining and the risk of lung cancer as modified by smoking habits (see page 46). Regardless of the method used to select a control group, little information can be obtained with only 29 cases who died from lung cancer, as determined by death certificates.

(b) The authors produced "matches" to each case by selecting those three persons entered in the register (of deaths and burials in the Hammar parish of Sweden) before and after each case, provided death was not caused by lung cancer, in the hope to match cases to controls according to similar chronological time of death. They thus produced $29 \times[3+3]=174$ "controls," and stated: "since there was no reason, however, to believe that time of death should be a confounding factor (13) (the method of selecting the referents having been applied for reasons of convenience only), the tuplets were not maintained in the analysis."
The identity of who matches whom having been destroyed, we are presumably left with two overall groups to compare, the lung cancer deaths (29 in number) and a "control" group of 174 nonlung cancer deaths. Do we still have a matched case-control study? Why did the authors match the way they did? In what way is the control group comparable to the group of 29 lung cases? Might it not happen that, by artificially selecting the size of a control group, one might bias the results in a given direction?

(c) Regarding exposure, the mining company furnished the assessment of worktime underground. As for smoking habits, the authors polled two former foremen, as well as viewing medical files. Where possible, independent information about smoking was obtained from different sources (this applies to 10 of the lung cancer cases), and the sources were contradictory in 2 of the 10 cases. Two cases were eliminated (and 3 referents) due to missing information, leaving only 27 cases under study. No details are given concerning the accuracy of the data furnished by the mining company regarding worktime underground, and the assessment of smoking habits is likely to be fraught with all sorts of biases, not to mention the fact that no account is given of how much smoking was involved.

(d) Our last point concerns the actual statistical analysis of the data. First, as is clear from tables 3 and 4 , there really are at most 19 cases of lung cancer available for study. In addition to the two 
cases already eliminated, a further eight seem to be lacking information on smoking habits. The authors claim to find a significant difference in the latency time between the nine nonsmokers and the ten smokers $(p=0.016$, one-tailed) via a t-test. When nothing is known of the time distribution of latency times, and when confronted with small sample sizes, a nonparametric technique would be acceptable, but a t-test is highly questionable.

In summary, the authors' hypotheses are important and provocative enough to seek relevant answers, but it is our belief that a far more intensive experiment, of a prospective nature preferably, would be necessary even to begin to provide insight about the relationship of mining and smoking to lung cancer.

Michael L Feldstein, PhD

Harvard School of Public Health

Boston, MA, USA

and

Pierre R Band, MD

Institut du Cancer de Montreal

Montreal, Canada

\section{Authors' reply}

Sir,

Certainly we share the summary view of Drs Feldstein and Bard that our hypotheses are provocative and perhaps also important. No doubt, a prospective approach would be desirable for further insight into the relationship of mining, smoking and lung cancer. Hopefully, our paper may stimulate such efforts to the benefit of miners' health and the scientific understanding of cancer causation in this occupational group.

\section{Comments on our study}

We also agree that only limited information can be obtained from our small-scale study of lung cancer deaths among miners, as is also formally reflected in the confidence interval of the rate ratio (table 4).
Since the $90 \%$ confidence interval already approximately encompasses a rate ratio of $0.11-2.2$, there is no definite conclusion of a reduced risk of lung cancer for smokers versus nonsmokers among the miners. Nevertheless our finding of relatively more cases among the nonsmokers seems inconsistent with the usually held view of a considerable (and at least fivefold) increase in the risk of lung cancer among smokers versus nonsmokers.

Concerning the "matching procedure," we regret the terminology since the procedure was merely one of selecting referents tantamount to a random selection from the register of deaths. In principle, therefore, our study should not be looked upon as a "matched" case-referent study but rather as a stratified one. It is important, though, that the referents represent the exposure frequency of the source population for the cases during the study period since, otherwise, the odds ratio, as obtained from a case-referent study, does not represent the incidence rate ratio of the disease, exposed individuals compared to nonexposed (cf 2,4).

As to the comparability of the case and the referent series, there are two aspects to the study. First, there is the evaluation of lung cancer mortality among the miners in comparison to the balance of the male population of the parish; second there is the investigation of the mortality among smoking versus nonsmoking miners. The fundamental aspects of comparability in case-referent studies are too far-reaching to be thoroughly dealt with in this reply, and we prefer therefore to refer to a paper on methodological asperts in the context of casereferent studies in occupational health epidemiology (2). It might suffice to add that we see no reason why the applied selection of our referent series should bias the results of the study in any specific direction, although - as in any epidemiologic study - the results could, with some likelihood, be a matter of chance.

Regarding the accuracy of data on worktime underground, it is explicitly stated that the induction-latency time may have been overestimated since some of the miners might have started their career in surface work and the exact point in 
time when each individual entered underground work is not known. However, we still persist in our suggestion that there is no reason to suspect a difference between smokers and nonsmokers in this respect.

In assessing smoking habits, we were probably on the conservative side, since individuals for whom the information was contradictory were considered to be smokers if they had lung cancer. As a matter of fact, we are aware of at least one miner (not in the study), who was classified as a smoker in the medical files, probably just because he had lung cancer, although he, in a personal interview with one of us, clearly stated that he had not been smoking for the last 30 a before developing lung cancer; therefore, medical files are not necessarily a reliable source of information about the smoking habits of lung cancer cases.

For the statistical testing of differences between induction-latency times for nonsmoking and smoking miners to develop lung cancer, a nonparametric technique could have been preferable and might have given a somewhat higher $\mathrm{p}$-value. On the other hand, too much emphasis should not be put on the p-value as such, although it reflects, to some extent, the possibility for generalization of the conclusion about a difference in induction-latency times.

\section{Supporting experiences}

Since we published our study, other data have appeared which might be of interest in this context. Thus, there is now another Swedish report (3), again showing more lung cancer deaths among nonsmoking miners than among those who smoke; Dahlgren found 4 lung cancer deaths out of 29 deaths among smoking miners versus 4 out of 15 among the nonsmokers. Dahlgren's study (3) includes all the miners of Boliden having died in that parish, and therefore there is no aspect of random variation for statistical evaluation as far as the specific mining population under study is concerned. It is another matter, however, if one wishes to extrapolate these observations to a general statement about the lung cancer hazard among smoking and nonsmoking miners.
Furthermore, an animal experiment (5) now also exists that is of great interest in this context. Thus smoking dogs exposed to radon daughters and uranium ore dust developed fewer respiratory cancers (nasal and lung cancers) than a group of nonsmoking dogs exposed to the same environment (20 dogs in each group; 2 cancers among the smokers versus 8 among the nonsmokers).

Although these various experiences may seem somewhat odd, there could be some rationale behind them. As we suggested, an increased thickness of the mucous sheath, particularly among smokers in a mine environment, could protect against the very short-ranging alpha radiation. It is interesting to read the discussion of Altshuler et al from 1964 (1) regarding the thickness of the mucous sheath and also the possibility of disease processes associated with mining that could change some of the dimensions involved with regard to the effective alpha radiation to the bronchial epithelium. Thus the possibility of hyperplasia is discussed as increasing the depth of basal cells, but there is also a suggestion that outer epithelial cells could be sloughed off, leaving the basal cells closer to the surface. There is also a suggestion that miners might have abnormally thick mucus and that the less energetic and penetrating $\mathrm{RaA}$ alpha radiation therefore could be completely ineffective in causing damage to the larger bronchi. Therefore, if our paper, as well as the other findings referred to $(3,5)$, would provoke researchers to go further into the mechanism of lung cancer induced by alpha radiation and the connected problems of risk evaluation, we would be very satisfied even if our observations finally turned out to be refutable.

\section{References}

1. Altshuler B, Nelson N, Kuschner M. Estimation of lung tissue dose from the inhalation of radon and daughters. Health phys 10 (1964) 1137-1161.

2. Axelson $O$. The case-referent (case-control) study in occupational health epidemiology. Scand j work environ health 5 (1979) 91-99.

3. Dahlgren E. Lungcancer, hjärtkärlssjukdom och rökning hos en grupp gruvarbetare. Läkartidningen 76 (1979) 4811-4814.

4. Miettinen OS. Estimability and estimation 
in case-referent studies. Am j epidemiol 103 (1976) 226-235.

5. Pacific Northwest Laboratory, Biology Dept. Study of the combined effects of smoking and inhalation of uranium ore dust, radon daughters and diesel oil exhaust fumes in hamsters and dogs: Final report. National Institute of Environmental Health Sciences, Richland, VA 1978. (HEW contract TD 0212).

\section{Olav Axelson \\ Department of Occupational Medicine University Hospital \\ S-581 85 Linköping, Sweden}

and

Lennart Sundell

Department of Occupational Medicine Regional Hospital

S-701 85 Örebro, Sweden

\section{Sawmill work and extrinsic allergic alveolitis}

Sir,

The authors of "Extrinsic Allergic Alveolitis in a Sawmill Worker" (vol 6, no 2, 1980 , pp 153-157) have apparently missed the fact that extrinsic allergic alveolitis, tentatively named wood trimmer's disease, has been described as a widespread and complicated health problem in the sawmill industry for the last 3 to $4 \mathrm{a}$ in Sweden.

With this Finnish report of one case the authors now take the opportunity to alert the readers about a "new health hazard in modern sawmill industry." If they had troubled themselves by reading any of the references given below, they would know that the problem has been recognized and subjected to much study - even reported at scientific meetings in Finland on two occasions (in 1977 and 1979). If attention had been paid to the Swedish data, an interesting discussion could have been given concerning the different findings of causative mold species to these reactions, which are probably the same in Sweden and Finland.
The serological data in the report do not provide information on whether antigen extracts representing Rhizopus, Paecilomyces and Mucor species were included in the precipitin analyses. Rhizopus has by far been found to be the dominating mold species in the trimming areas of Swedish sawmills, probably because of its very rapid growth at kiln drying temperatures in comparison with many other opportunistic spore producing molds. Finally, it would have been interesting to know how the authors relate their mold problem to the kiln drying procedure, which I assume has been employed for wood drying also in the saw mill in which their case worked. In Sweden we have mainly traced the problem to this operation in modern saw mills, and the technical schedules for the kiln drying are currently critically examined in order to create less favorable conditions for the opportunistic molds to grow during the drying process.

\section{References}

1. Belin L. Justerverkssjuka - ett aktuellt medicinskt problem inom svensk ságverksindustri. In: Institute of Occupational Health, ed. 26 Nordiska yrkeshygieniska mötet. Helsinki 1977, pp 138-139.

2. Belin L. Wood trimmer's disease - An allergic reaction to moulds in Swedish saw mills. J allergy clin immunol 61 (1978) 160 .

3. Belin L. Wood trimmer's disease - An allergic reaction to moulds in Swedish saw mills. In: European Academy of Allergology and Clinical Immunology, ed. Annual meeting of the European Academy of Allergology and Clinical Immunology, Helsinki 1979 , p. 50.

4. Belin L, Göransson K, Wimander K, Wåhlén P. "Justerverkssjuka" — en immunkomplexsjukdom inom svensk sågverksindustri. Arbetrskyddsstyrelsen, Stockholm 1976. (Utbildning 2:76).

5. Belin L, Wallentén $B$, Wimander $K$. Wood trimmer's disease from moulds on planks. Arbetsmiljö 10 B (1977) 19.

Lars Belin, MD

Occupational Health Centre and

Department of Allergology

First Medical Service

Sahlgren's Hospital

S-413 45 Göteborg, Sweden 